\title{
Laboratory Evaluation of Ground Tire Rubber in Stone Mastic Asphalt
}

\author{
R. Muniandy*1, A. A. Selim², S. Hassim¹, and H. Omar ${ }^{1}$ \\ ${ }^{1}$ Department of Civil Engineering, University Putra, Malaysia \\ ${ }^{2}$ Department of Civil \& Environmental Engineering, South Dakota State University, Brookings, SD, USA
}

Received 23 April 2003; accepted 5 November 2003

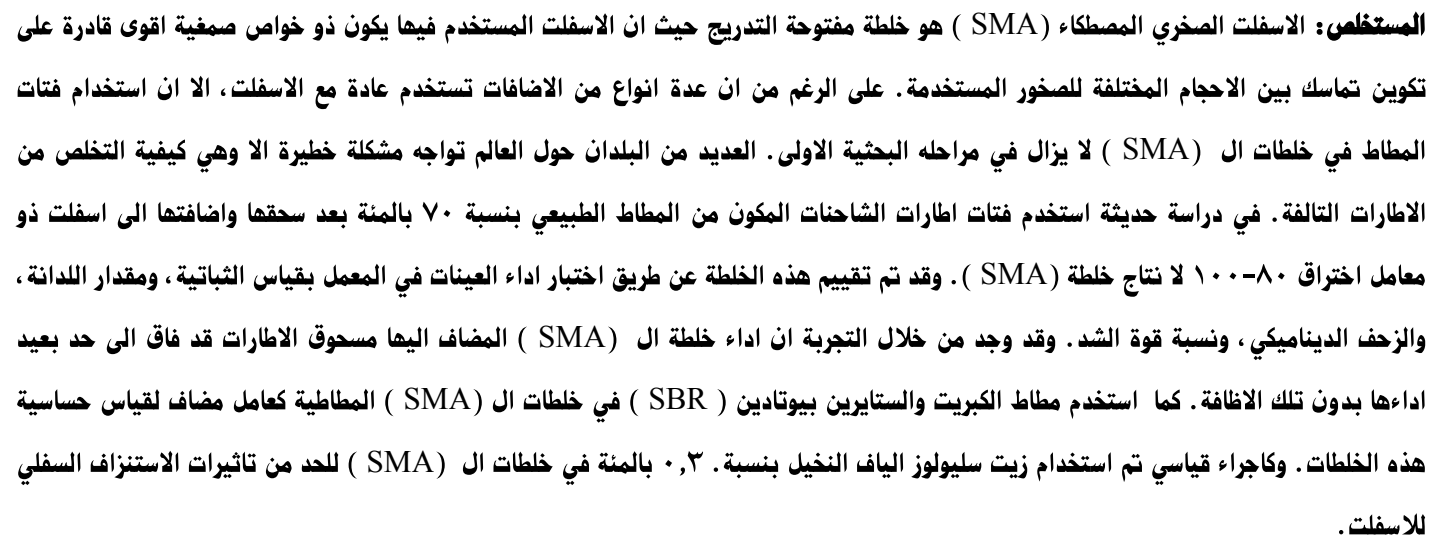

الهزردات الهنتاهية: أسفلت من الحجر الصمفي ، مطاط، أطار، اعادة التدوير ، ععدل (مطور) ، الطرق.

\begin{abstract}
Stone mastic asphalt (SMA) is a gap-graded mix whereby stiffer asphalt cement is required to bind the stone matrix or arrangement of stones together. Although various asphalt additives are traditionally available, the use of rubber crumbs in SMA is still a new rresearch endeavor. Many countries around the world are facing serious problems on what to do with reject or discarded tires. In the present study, commercial truck tires, containing 70\% natural rubber, were ground and pre-blended in 80-100 penetration asphalt for use in SMA mixtures. An assessment was made of the laboratory performance of rubberized SMA in terms of stability, resilent modulus, dynamic creep and tensile strength ratio. It was observed that the performance of SMA with ground tire rubber was for superior as compared to SMA mix with unmodified asphalt. Sulfur and Styrene Butadeline Rubber (SBR) were used in rubberized SMA mixes as additives to test the sensitivity of SMA mixtures. As standard practice a $0.3 \%$ newly developed cellulose oil palm fiber was used in SMA to minimize the asphalt drain-down effects.
\end{abstract}

Keywords: Stone mastic asphalt, Rubber, Tire, Recycling, Modified, Roads

\section{Introduction}

Stone mastic asphalt (SMA) is a gap-graded mix with a skeletal stone-to-stone arrangement that requires a higher viscosity asphalt binder to keep the interlocked aggregates bound and intact. The interlocking nature of the mix is expected to increase the stability and to minimize the lateral displacement of the aggregates that tend to reduce

*Corresponding author E-mail: ratnas@eng.upm.edu.my permanent deformation or rutting of the mix. The concept was first developed in Germany in the early sixties. It was further developed in the United States in the early 1990s, (Selim et al., 1994).

Whenever a conventional dense graded aggregate gra dation is altered to a gap graded matrix , the voids in mineral aggregates (VMA) increases considerably. Such a void content must be filled with a mastic that has excellent shear properties so as to hold the gap graded coarse aggregate matrix over a long period of time. In order to achieve this, recycled ground tire rubber of \#40 mesh 


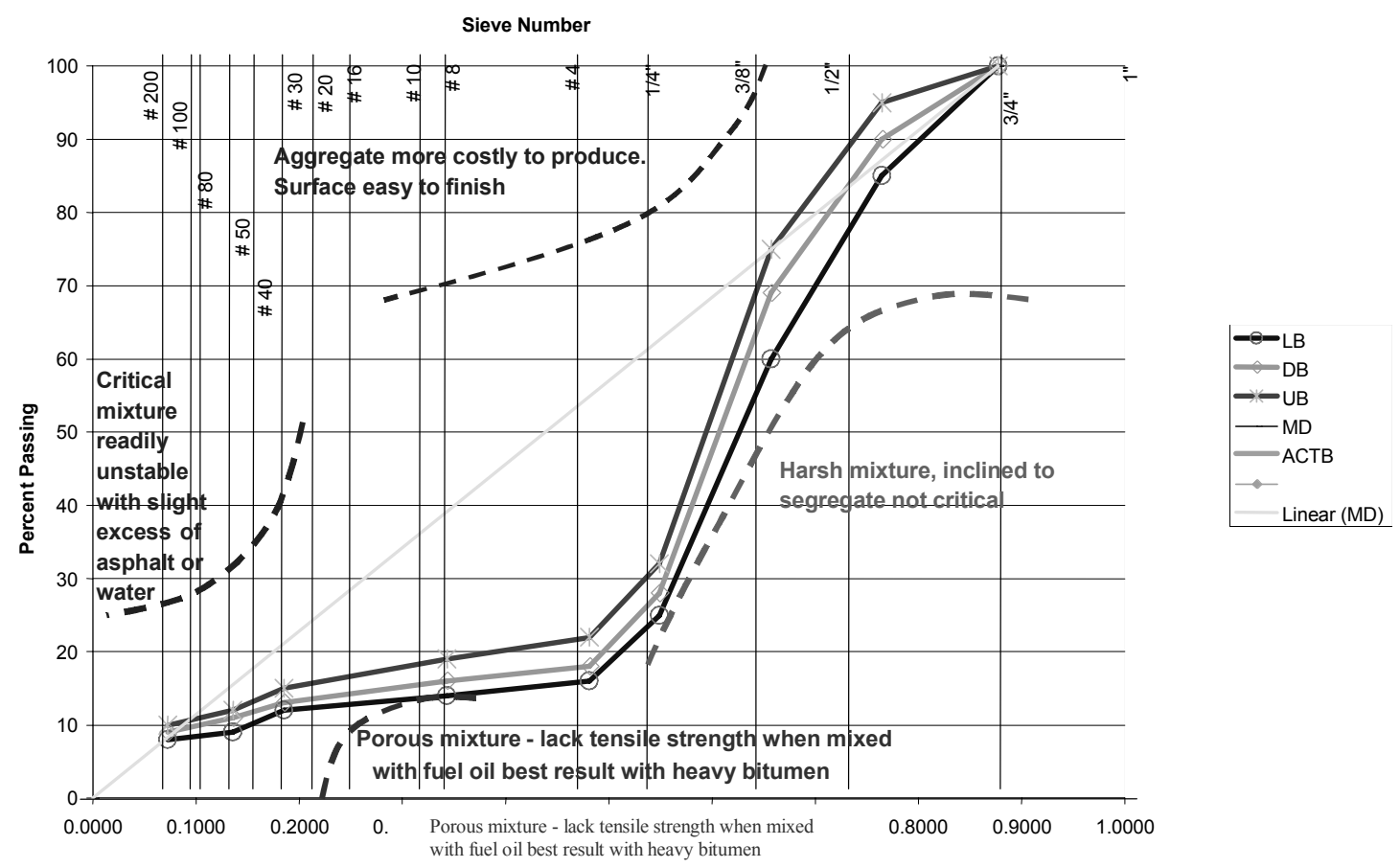

Figure 1. Stone mastic asphalt (SMA) and conventional gradations

from shredded tires was used in the pre-blending of unmodified 80-100 asphalt, (Lundy et al., 1987) (SMA in general in prone to asphalt drain-down during mix storage and transportation to the construction site). Even after the placement of the mix, the softening of the mastic during hot days tends to slowly drain down the asphalt. This slow drain down effect of the binder is further accelerated by the contact pressure from wheel loading which may result in the ultimate loss of bitumen from the top part of the asphalt layer. To minimize this problem cellulose fibers were used.

\section{Material Characterization}

SMA is a high strength mix that requires good quality aggregates. Inferior quality aggregates may be crushed upon repeated loading that may in turn alter the stone matrix posture entirely. Therefore, aggregate quality must be controlled to ensure the superior performance of SMA mixtures, (Bukowski, 1991).

Since granite is abundantly available in Malaysia, it was identified as a prime candidate for use in SMA mix. In our research, the Public Works Department specifications (PWD), (Public Works Department, 1985), for aggregate properties were adopted in for mulating stone mastic asphalt, Table 1. A typical gradation was formulated that would give higher stability and reliability with a maximum size of $14 \mathrm{~mm}$. Approximately, $80 \%$ of the aggregates were larger than $2 \mathrm{~mm}$, and more than 70 percent larger than $8 \mathrm{~mm}$, Figure 1.

Traditional $80 / 100$ penetration asphalt is considered to be too soft for use in SMA. It has to be modified to increase the viscosity. Polymers have been traditionally used to modify asphalts for specific applications.
Table 1. Granite aggregate properties used in SMA mix

\begin{tabular}{|c|c|c|c|}
\hline No. & Type of Test & Result \% & $\begin{array}{l}\text { PWD } \\
\text { Requirement }\end{array}$ \\
\hline 1 & L.A Abrasion & 19.70 & $\leq 30 \%$ \\
\hline 2 & Crushing Value & 26.20 & $\leq 30 \%$ \\
\hline 3 & Impact Value & 12.6 & $\leq 15 \%$ \\
\hline 4 & $\begin{array}{ll}\text { Soundness } & \text { Test } \\
\text { (Sodium Sulfate) } & \end{array}$ & 1.76 & $\leq 15 \%$ \\
\hline 5 & Polishing Stone Value & 50.9 & $\geq 49$ \\
\hline 6 & $\begin{array}{ll}\text { Flakiness } & \text { and } \\
\text { Elongation } & \text { Test ( } 3: 1 \\
\text { ratio) } & \end{array}$ & 17.1 & $\leq 20 \%$ \\
\hline 7 & Specific Gravity & 2.62 & $\geq 2.60$ \\
\hline 8 & Water absorption & 0.469 & $\leq 2 \%$ \\
\hline
\end{tabular}

Table 2. Physical properties of rubberized asphalt

\begin{tabular}{|c|c|c|c|c|c|}
\hline \multicolumn{3}{|c|}{ Asphalt Blend* } & $\begin{array}{c}\text { Penetration } \\
(\mathrm{mm})\end{array}$ & $\begin{array}{l}\text { Softening } \\
\text { Point }\left({ }^{\circ} \mathrm{C}\right)\end{array}$ & $\begin{array}{c}\text { Thin Film } \\
\text { Oven }\end{array}$ \\
\hline \multicolumn{3}{|l|}{ UMA } & 85.7 & 52.3 & 0.003 \\
\hline \multicolumn{3}{|l|}{ TRA2 } & 79.3 & 63.3 & 0.009 \\
\hline \multicolumn{3}{|l|}{ TRA3 } & 71.5 & 68.2 & 0.010 \\
\hline \multicolumn{3}{|l|}{ TRA4 } & 62.0 & 70.3 & 0.011 \\
\hline \multicolumn{3}{|c|}{ TRA4-2.2S } & 61.7 & 70.3 & 0.009 \\
\hline \multicolumn{3}{|c|}{ TRA4-5B } & 60.3 & 71.0 & 0.007 \\
\hline *UMA & $=$ & \\
\hline \multicolumn{6}{|c|}{$=$ Tire rubber asphalt with $2 \%$ rubbe content by weight of } \\
\hline \multicolumn{6}{|l|}{ TRA3 } \\
\hline \multicolumn{6}{|l|}{ TRA4 } \\
\hline \multicolumn{6}{|c|}{$\begin{aligned} \text { TRA4-2.2S }= & \text { Tire ru } \\
& \text { butanol }\end{aligned}$} \\
\hline \multicolumn{2}{|c|}{ TRA4-5B = } & $\begin{array}{l}\text { Tire rul } \\
\text { by wei }\end{array}$ & $\begin{array}{l}\mathrm{r} \text { asphalt with } 4 \% \\
\text { of asphalt }\end{array}$ & ber content ar & 6 sulfur \\
\hline
\end{tabular}


However, the use of polymers increases the overall cost of asphalt mix production. Recent experiences in polymer modified asphalt (PMA), (Bukowski, 1991) showed that it costs at least three times more compared to conventional asphalt. Tire rubber from recycled shredded tires were pulverized to \#40, which is about 450 micron size. The tire rubber powder was checked for deleterious material like particles from the steel belting that could have been *mixed with the tire powder during the shredding, grinding, and separation process. This was done to ensure the purity of the selected material. The unmodified asphalt was blended with $2 \%, 3 \%$ and $4 \%$ ground tire rubber. The physical properties of the tire rubber modified asphalt are shown in Table 2. Sulfur and styrene butadiene random (SBR-Butanol) were also used in our study to check the sensitivity of SMA mixes.

\section{Marshall Mix Design}

Marshal mix design was carried out in accordance with the American Standard for Testing and Materials (ASTM) D1559. Fifteen $100 \mathrm{~mm}$ diameter Marshall specimens were prepared for each tire rubber blended asphalt. Each speciment required approximately 1200 grams of granite aggregates. A total of 60 batches were used in the preparation of SMA samples. Four sets of asphalt blended with $2 \%, 3 \%$, and $4 \%$ tire rubber and one unmodified set were prepared for the mix design.

The aggregate samples were heated in an oven to $170^{\circ} \mathrm{C}$ while the asphalt blends were heated to $165^{\circ} \mathrm{C}$ based on the viscosity-temperature of the asphalt. For each asphalt type, five sets of three specimens, each with an asphalt content of $4 \%, 5 \%, 6 \%, 7 \%$ and $8 \%$, were prepared. A $0.3 \%$ cellulose fiber by weight of aggregates were used in all SMA samples. The compaction of the SMA mixtures was done using an automatic compactor with a standard 50 blow on each side. It is a common practice in Malaysia to use 50 blow Marshall compaction for hot mix asphalt mixtures.

\section{Optimum Asphalt Content}

The optimum asphalt content for each rubber blend was determined at maximum bulk density, maximum stability, and at 4\% air voids using the Asphalt Institute Method, Table 3. The average of four optimums was considered in the preparation of specimens for performance tests. Additional specimens were made with the optimums of each asphalt blend.

Marshall properties tests were carried out in accordance with ASTM D1559. The performance of the rubberized and control samples are shown in Figures 2 to 7 and in Table 3. The resilient modulus test was carried out in accordance with ASTM D4123, Figure 4. Samples with more than 4 percent tire rubber blended asphalt were found to have non-desirable properties. Contents higher than $4 \%$ tire rubber were tried. However, it was found to be very difficult to blend the pulverized tire beyond $4 \%$ due to clumping and dispersion. Hence the study focused on a maximum tire rubber content of $4 \%$ (by weight of asphalt) only.

Marshall tests with various proportions of tire blend showed that SMA with 4\% ground tire rubber (TRA4) displayed better properties compared to other SMA mixtures. However, SMA with a tire rubber blend of more than $4 \%$ did not display good Marshall properties.

The workability was greatly affected. Hence, the results of SMA with greater than $4 \%$ tire rubber are not dis-

Table 3. Results of SMA mix performance

\begin{tabular}{lclllllll}
\hline Mix & $\mathbf{M}_{\mathbf{R}}(\mathbf{M P a})$ & $\begin{array}{l}\text { Stability } \\
(\mathbf{k N})\end{array}$ & Flow & $\begin{array}{l}\text { Bulk } \\
\text { Density }\end{array}$ & $\begin{array}{l}\text { VMA } \\
(\mathbf{\%})\end{array}$ & VTM (\%) & VFA (\%) & $\begin{array}{l}\text { Optimum } \\
\text { AC }\end{array}$ \\
\hline UMA & 3436.3 & 12.65 & 3.43 & 2.28 & 18.16 & 4.95 & 72.72 & 5.86 \\
TRA2 & 3612.7 & 14.31 & 4.50 & 2.311 & 17.11 & 3.62 & 78.86 & 5.9 \\
& & & & & & & & \\
TRA3 & 3764.7 & 15.01 & 4.76 & 2.313 & 16.96 & 3.44 & 79.70 & 6.0 \\
& & & & & & & & \\
TRA4 & 3942.0 & 17.30 & 4.66 & 2.321 & 16.76 & 5.60 & 66.58 & 6.1 \\
& & & & & & & & \\
TRA4-2.2S & 4275 & 17.88 & 4.60 & 2.35 & 17.82 & 4.95 & 72.31 & - \\
TRA4-5B & 4885 & 18.31 & 4.69 & 2.35 & 17.79 & 5.04 & 69.87 & - \\
\hline
\end{tabular}

Table 4. Permanent deformation of rubberized SMA

\begin{tabular}{lrrrrrrrr}
\hline \multicolumn{1}{c}{ Sample } & \multicolumn{9}{c}{ Load Cycle } \\
\cline { 2 - 9 } & \multicolumn{9}{c}{ 1\% Strain } & \multicolumn{3}{c}{ 3\% Strain } \\
\hline & 1 & 2 & 3 & Ave & 1 & 2 & 3 & Ave \\
UMA & 52 & 92 & 61 & 68.3 & 1711 & 1755 & 2100 & 1855.3 \\
TRA4 & 79 & 71 & 90 & 80.0 & 2782 & 2712 & 2854 & 2782.7 \\
TRA4-2.2S & 180 & 105 & 158 & 147.7 & 3244 & 3004 & 3328 & 3192.0 \\
TRA4-5B & 125 & 100 & 150 & 125.0 & 8360 & 4641 & 4885 & 5962.0 \\
\hline
\end{tabular}




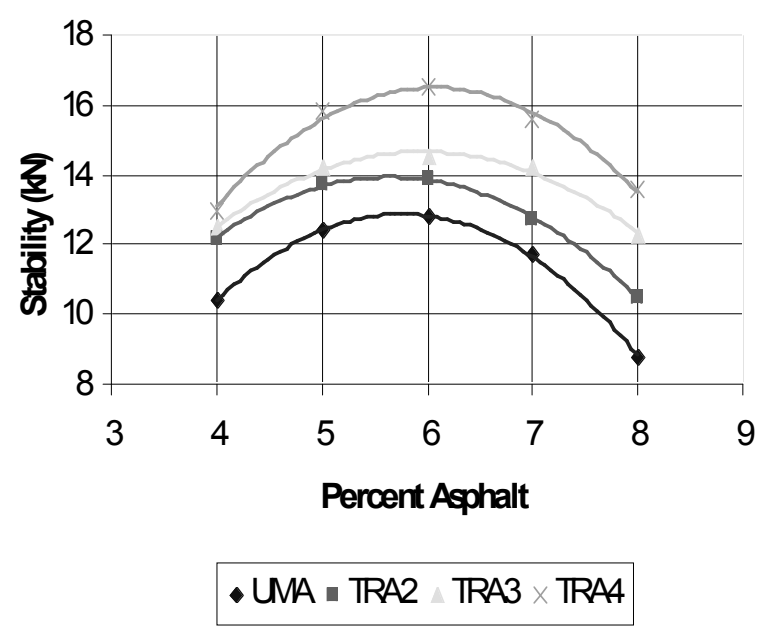

Figure 2. Marshall stability vs asphalt blend

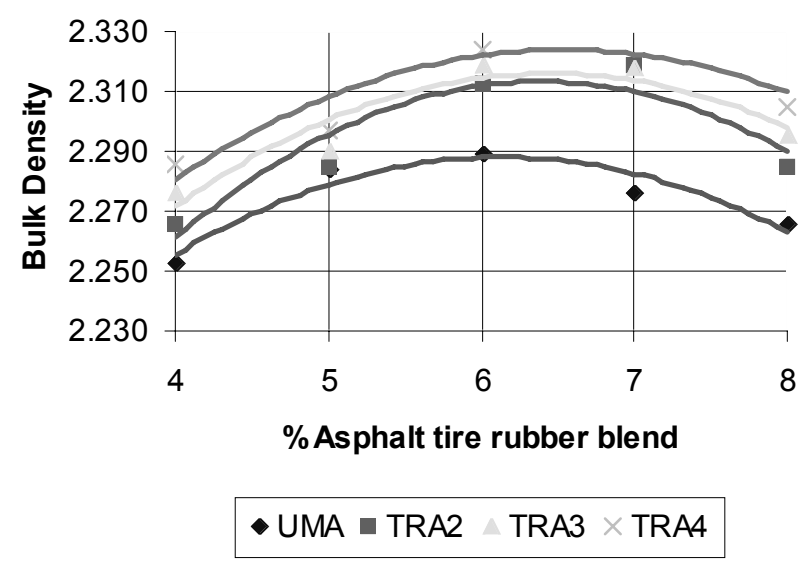

Figure 3. Bulk density vs asphalt blend content

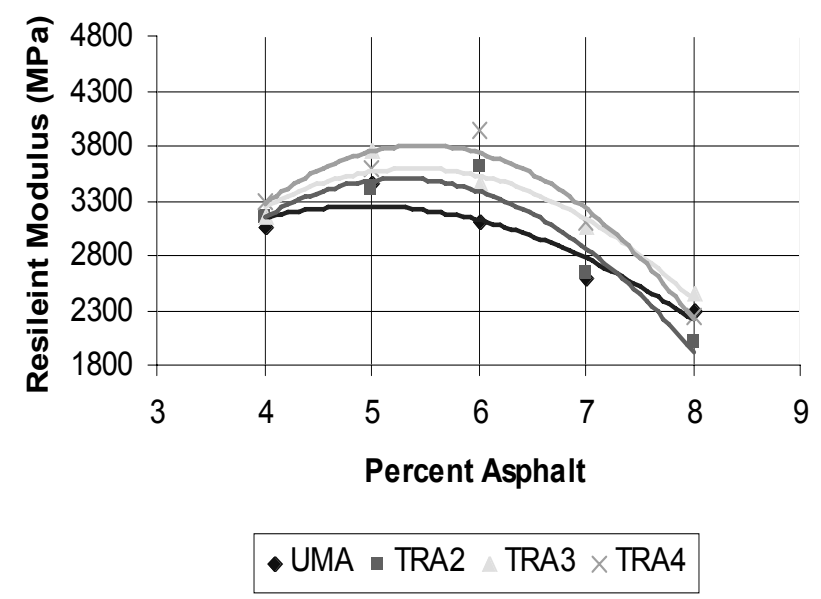

Figure 4. Resilient modules vs \% asphalt blend content

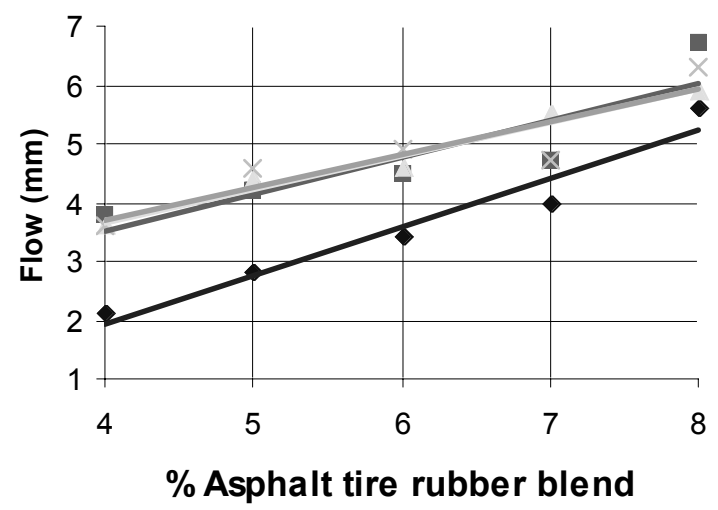

- UMA - TRA2 TRA3 $\times$ TRA4

Figure 5. Flow vs asphalt blend content

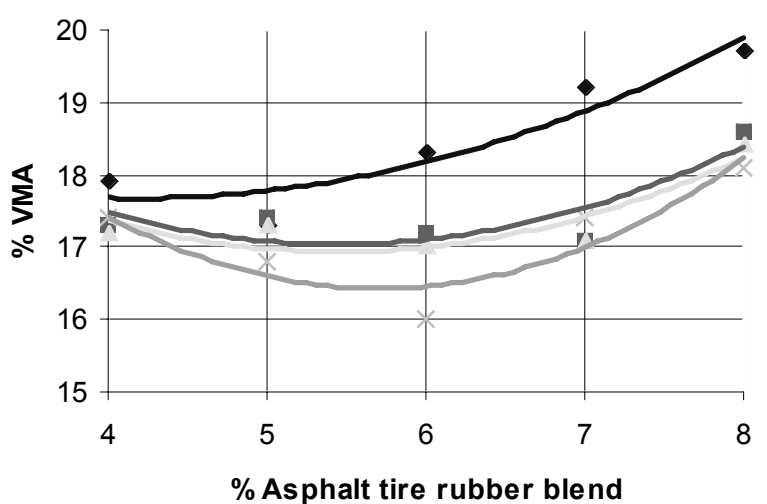

$\bullet$ UMA $\square$ TRA2 $\triangle$ TRA3 $\times$ TRA4

Figure 6. VMA vs asphalt blend

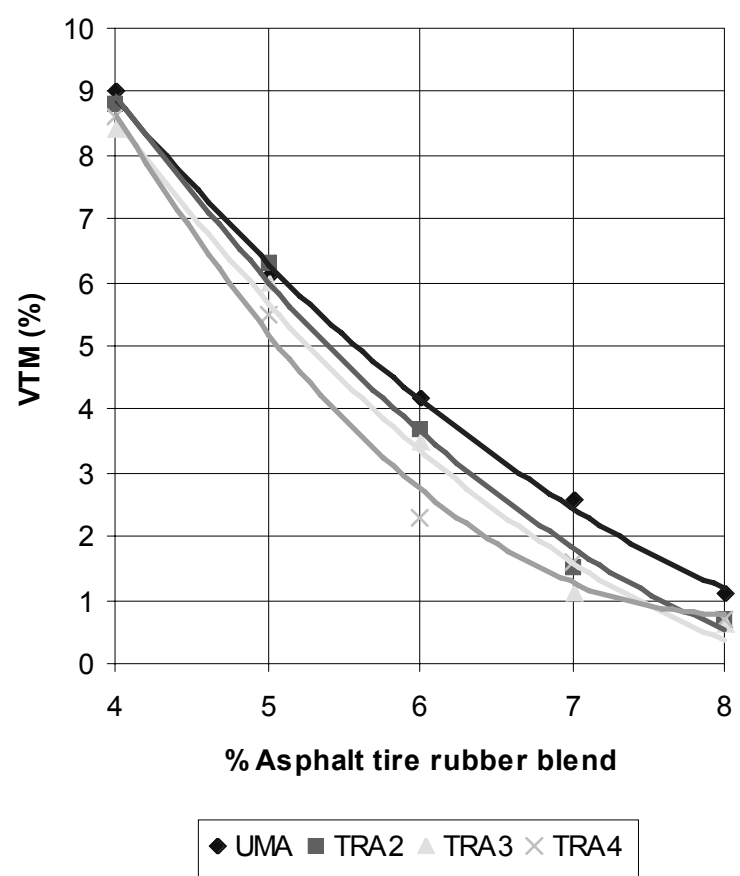

Figure 7. VTM vs asphalt blend content 


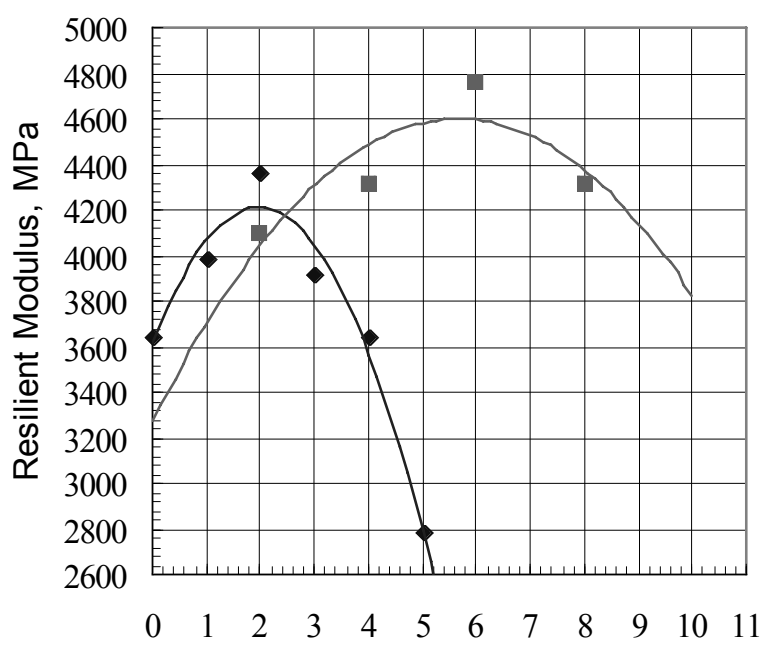

$\%$ Sulfur/Butanol in $4 \%$ tire rubber blend

- Sulfur a Butanol

Figure 8. Resilient modulus vs sulfur and butanol content

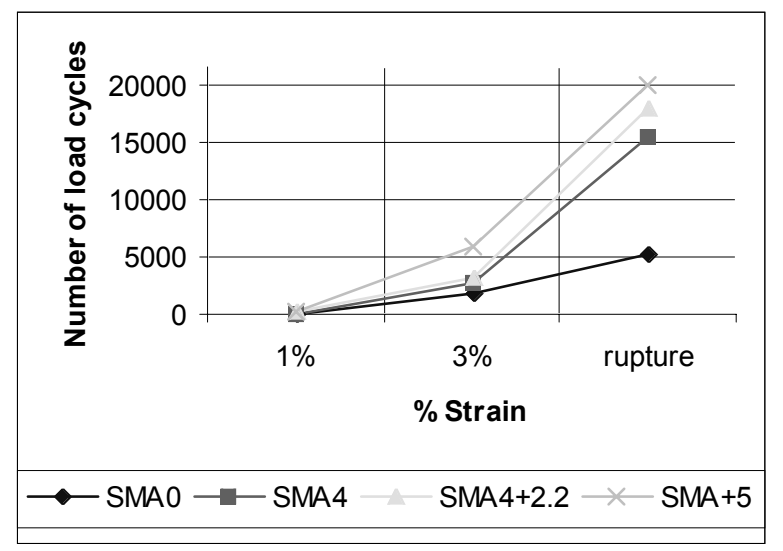

Figure 9. Strain vs number of load cycles

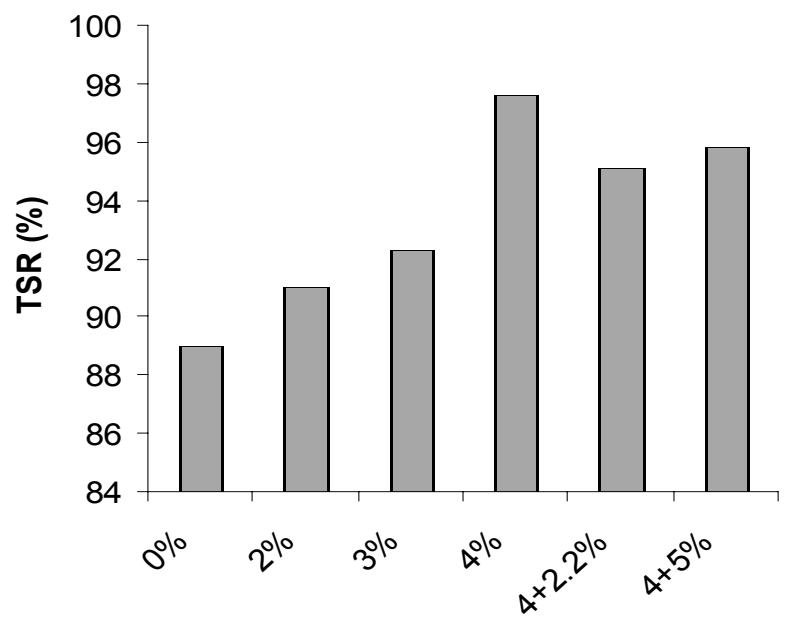

Type of asphalt blend

Figure 10. Tensile strength ratio of SMA mix cussed in this paper.

A sensitivity analysis was carried out on SMA-4 using sulfur and a styrene butadiene rubber product (Butanol). A total of fifteen samples were prepared and tested for Marshall properties, Table 3. The optimum sulfur and butanol contents were determined by preparing and testing 15 SMA specimens with sulfur proportions of 1,2,3,4, and $5 \%$ and 15 specimens with $2,4,6$, and $8 \%$ butanol by weight of asphalt tire rubber blend. Figure 8 shows the optimum sulfur and butanol content determined from the resilient modulus test.

\section{Dynamic Creep Performance}

SMA specimens were tested for permanent deformation in the uniaxial repeated compressive load. Sets of three specimens were made for each asphalt tire rubber blend at their individual optimum asphalt content and trimmed to $50 \mathrm{~mm}$ with a $2: 1$ ratio of the diameter. The specimens were then tested in accordance with ASTM D3497 to determine the number of load cycles to reach $1 \%$ strain , 3\% strain and ultimate failure, Table 4 and Figure 9. An Australian IPC MATTA machine was used in the testing of the SMA specimens. The selected test parameters were as follows:

Test temperature $\quad: 50^{\circ} \mathrm{C}$

Pulse Width : 500ms

Pulse Period : $\quad: 2000$

Test Load Stress $\quad$ : $500 \mathrm{kPa}$

\section{Moisture Induced Damage Analysis}

Roads in tropical countries like Malaysia are exposed to extreme moisture conditions. As such, it was deemed appropriate to carry out a moisture induced damage test on SMA samples. The samples were prepared and tested using the Modified Lottman Test in accordance with AASHTO T283. Two sets of three specimens for each test were prepared. One set of samples was used as a control while the other set was vacuum saturated at 28 in $\mathrm{Hg}$ with water for 25 minutes. Both sets (control and conditioned) were then tested for indirect tensile strength at $25^{\circ} \mathrm{C}$ using a loading rate of $51 \mathrm{~mm} /$ minute. The tensile strength ratio (TSR) of the samples was determined as a ratio of conditioned strength over control strength, Figure 10. A minimum of 0.7 is generally specified. The higher the TSR, the higher the durability of the mix.

\section{Discussion}

The Marshall mix properties of SMA with tire rubber blends of $2 \%, 3 \%$, and $4 \%$ generally increased with a gradual increment in optimum asphalt content. The optimum asphalt contents ranged between 5.86 to $6.10 \%$. 
SMA with $4 \%$ tire rubber showed higher values in terms of stability and resilient modulus. A sensitivity analysis on SMA- $4 \%$ tire rubber with $2.2 \%$ sulfur and $5 \%$ SBR additive greatly improved the SMA mixture's permanent deformation or rut potential. It was found that SMA with $4 \%$ blend took 80 load cycles to reach $1 \%$ strain and 2782 load cycles to reach $3 \%$ strain while the control SMA mix displayed a much lower value of 68.3 cycles for $1 \%$ and 1855 cycles for $3 \%$ strain levels. The addition of a small amount of sulfur and butonal, separately, resulted in a marked increase in the dynamic creep performance of the mix. The addition of sulfur $2.2 \%$ by weight of rubberasphalt blend increased the load cycles to 148 for $1 \%$ strain and to 3192 for $3 \%$ strain. However, the addition of $5 \%$ butanol by weight of rubber-asphalt blend had the highest value. It took 5962 cycles to reach the $3 \%$ strain level and almost 20,000 load cycles to failure. The control mix on the average failed at 5181 cycles.

The indirect tensile test also showed that all SMA mixes displayed a tensile strength ratio of more than $70 \%$. SMA with $4 \%$ tire rubber without any additives showed a remarkable $98 \%$ TSR. However, SMA with $4 \%$ tire rubber and additives did not improve the moisture damage of SMA. Instead lower TSR values of $95 \%$ and $96 \%$, respectively, were displayed.

\section{Conclusions}

In conclusion, the rubberized stone mastic asphalt mix has shown great promise. This mix may be able to supersede the conventional mix. Since SMA requires a stiff binder the traditional 80/100 penetration asphalt can be blended with recycled ground tire rubber. This will give good binding properties for SMA performance. A cost effective SMA with reject or discarded tire rubber will give excellent pavement performance not only in tropical regions with high rainfall, but also in regions with high temperatures. The laboratory study has shown that there is a great potential for ground tire rubber for use in SMA, up to $4 \%$ with $0.3 \%$ cellulose oil palm fiber. However, a field trial needs to be carried out to evaluate its full potential.

\section{References}

Bukowski, J., 1991, "SMA comes to USA," Journal of the National Asphalt Pavement Association Vol.6, No.2, p.5.

Lundy, J.R., Hicks, R.G., Richardson, and E., 1987, "Evaluation of Rubber Modified Asphalt Performance Mt. St. Helens Project," Asphalt Pavemen Technology, Proceedings Associations of Technologists, Vol.56, pp.573-598.

Public Works Department, 1985, "Manual of Quartzite Based Stone Matrix Asphalt Mixtures (SMAM)", Proceedings of the third Materials Engineering Conference 804, ASCE, p.635-642. 